\title{
The NCeSS Portal - a Web 2.0 Enabled Collaborative Virtual Research Environment for Social Scientists
}

\author{
Xiaobo Yang ${ }^{1}$, Rob Allan ${ }^{2}$, June Finch ${ }^{3}$ \\ ${ }^{1}$ STFC e-Science Centre, Daresbury Laboratory \\ Warrington WA4 4AD, UK \\ $\mathrm{x} \cdot \mathrm{yang} @ \mathrm{dl} \cdot \mathrm{ac} \cdot \mathrm{uk}$ \\ ${ }^{2}$ STFC Computational Science and Engineering Department, Daresbury Laboratory \\ Warrington WA4 4AD, $U K$ \\ r.j.allan@dl.ac.uk \\ ${ }^{3}$ National Centre for e-Social Science, Arthur Lewis Building, Oxford Road \\ Manchester M13 9PL, UK june.finchencess.ac.uk
}

\begin{abstract}
In this paper, we are going to discuss a Sakai-based virtual research environment (VRE) - the NCeSS (National Centre for e-Social Science) Portal, for research scientists to tackle today's ever complex challenges. This portal is being developed for social science community as part of the UK Economic and Social Research Council (ESRC) e-Infrastructure Project. In particular we will investigate how Web 2.0 tools help scientists carry out their everyday research activities. Furthermore, with support from leading IT companies like Google and Yahoo!, it is nowadays possible to easily make use of the huge amount of data exposed by them for example the geographical data. This greatly enhances the capability of today's collaborative virtual research environments.
\end{abstract}

\section{INTRODUCTION}

The e-Infrastructure project is a 3-year project starting from January 2007 funded by the UK Economic and Social Research Council (ESRC). This project aims to build "an eInfrastructure to provide social scientists integrated access to a variety of research resources" [1]. This paper is not going to describe the project itself but focusing on development of the NCeSS Portal - a Web 2.0 enabled collaborative virtual research environment (VRE) for social scientists.

\section{A. Web 2.0}

Web 2.0 was originally driven by IT companies like Google and internet users (grass-roots) rather than academia. In his article “What Is Web 2.0" O'Reilly [2] pointed out several core competencies of Web 2.0 covering from service to user interface. Although there does not exist a precise definition of Web 2.0, the way people use the Internet has changed quite a lot in the past several years. Most of all, the Web is becoming a platform for collaboration. Without users' contribution, it is impossible for web sites like www.flickr.com (photo sharing) and Www. youtube.com (video sharing) to gain interest from people as they do now.

\section{B. Virtual Research Environments}

Unlike Web 2.0, virtual research environments are driven by academia. The UK Joint Information Systems Committee (JISC) has invested in this area since 2004. And recently VRE systems in other countries like Australia and New Zealand are gaining more and more attention. According to JISC, "the purpose of a VRE is to help researchers in all disciplines manage the increasingly complex range of tasks involved in carrying our research" (see http: //www.jisc.ac.uk/programme_vre.html).

The rest of this paper is organised as the following. First we will give a brief introduction of the Sakai-based virtual research environment. Then we will introduce Web 2.0 tools within this VRE system with concluding remarks presented at the end.

\section{WEB 2.0 TOOLS IN A SAKAI-BASED VRE SYSTEM}

\section{A. Sakai-based VRE system}

Sakai (www.sakaiproject.org) is a flexible eLearning platform targeting the high education market. It has a set of services and tools integrated for completing its core tasks such as data management and role-based access control. The beauty of Sakai resides in the easiness for developers to extend the framework. Services and tools can be plugged in or removed from the platform on demand. This feature is key to VRE systems. Such a Sakai-based VRE architecture has been discussed in [3].

As we can see from Fig. 1, a bunch of services reside in the cloud of a VRE system. Such a VRE system provide users services either through some APIs or web applications which can be utilised directly by end-users. Sakai provides many services mentioned in Fig. 1 except grid services.

\section{B. Blog and Wiki}

Sakai comes with some built-in collaborative tools, for instance, chat (instant messaging) and schedule (calendar). 


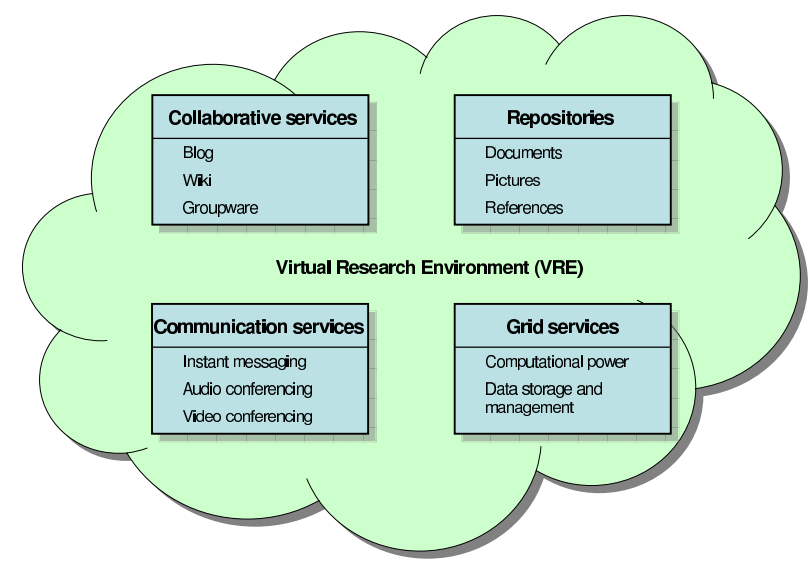

Fig. 1. Service-based virtual research environments

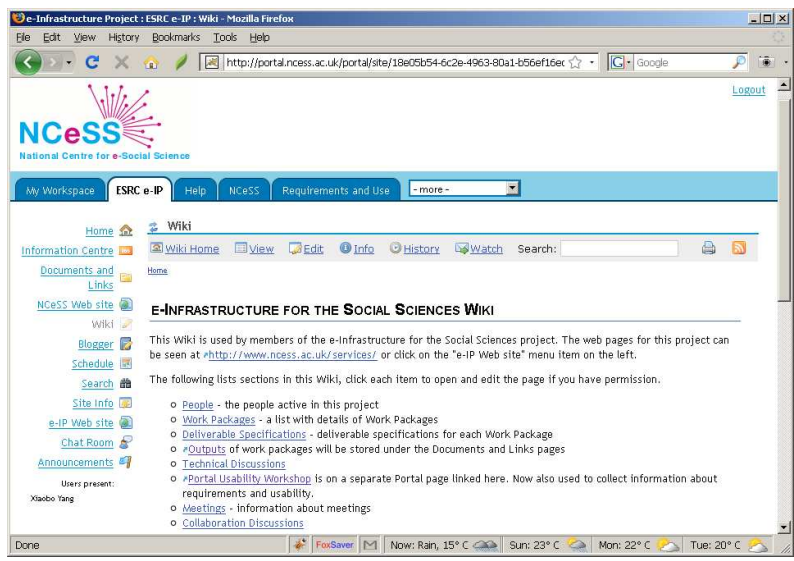

Fig. 2. A screenshot of the wiki tool from the ESRC e-IP worksite within the NCeSS Portal

Among those tools, blog and wiki are two typical Web 2.0 applications. Within a VRE system, a researcher can use blog to publish documents, e.g., ideas, notes, tutorials, papers, about his / her research projects. Then other researchers who have similar interest will have chance to consume such kind of knowledge. This is quite important when new researchers come into a particular research topic. Although not as formal as conference / journal publications, blog can provide the latest information of its owner's research.

While blog is typically for personal usage, wiki are normally used by groups. By providing editable web pages, wiki is ideal for writing research proposals, reports and papers. The Wiki tool has been extensively utilised by researchers involved in the e-Infrastructure project. In particular, it is being utilised in project management, for instance, setting up project meetings. With the resource tool, links can be set up easily to point to documents within a in-built repository. A screenshot of this tool from the ESRC e-IP worksite within the NCeSS Portal is illustrated in Fig. 2.

Both blog and wiki allow feedbacks from their readers which is useful to harness collective intelligence - the central principle of Web 2.0 by O'Reilly [2]. This is in particular important in today's research activities. Collaboration such as mutual visiting, workshops, conferences has already been set up in academia. But more efficient collaborative toolsets are required to realise seamless collaborative anywhere at anytime so that collective intelligence can be harnessed by individual researcher or research group.

\section{Mashup}

Mashup web sites integrate contents retrieved from a variety of services such as news feeds, maps and weather forecast reports. Since companies like Google and Yahoo! opened APIs for accessing geographic data, mapping mashup has become the majority of all mashup applications according to www. programmableweb. com/mashups ${ }^{1}$.

Using Yahoo! Maps web services, we have created a prototype mapping mashup application in our VRE system. Mapping mashup is in particular useful in some research fields in social science studies. For example, geographic data has already been collected and analysed by researchers from various background such as flooding and earthquake. Prior to APIs like Google Maps, it was a strenuous task to collect as much information as those provided by Google. Now with these APIs researchers are freed with the map but can focus on challenges they should tackle.

\section{CONClusions}

In this paper, we have described the NCeSS Portal, a Web 2.0 enabled collaborative virtual research environment for social scientists. Gradually Web 2.0 converts the Internet into a platform for collaboration. Here we want to harness the Web 2.0 collective intelligence from all researchers within virtual research environments to support research activities more efficiently. With tools like blog and wiki come from Sakai, our Sakai-based VRE system demonstrates that Web 2.0 helps researchers work more closely and collaboratively. Furthermore map services provided by companies like Google and Yahoo! bring scientists chances to quickly combine their research data with these map services. Mapping mashup will play an important role in research fields related to geography. In the future, there are more work to be carried out for example to study single sign-on within our portal since a project can have researchers from more than one university.

\section{REFERENCES}

[1] M. Daw, R. Procter, Y. Lin, T. Hewitt, W. Jie, A. Voss, K. Baird, A. Turner, M. Birkin, K. Miller, W. Dutton, M. Jirotka, R. Schroeder, G. de la Flor, P. Edwards, R. Allan, X. Yang, and R. Crouchley, "Developing an e-infrastructure for social science," in Proc. the 3rd International Conference on e-Social Science, Ann Arbor, Michigan, USA, Oct. 2007.

[2] T. O'Reilly. (2005, Sept.) What is Web 2.0. [Online]. Available: http://www.oreillynet.com/pub/a/oreilly/tim/news/2005/09/30/whatis-web-20.html

[3] X. Yang and R. Allan, "Sakai VRE demonstrator project: Realise eResearch through virtual research environments," WSEAS Transactions on Computers, vol. 6, no. 3, pp. 539-545, Mar. 2007.

\footnotetext{
${ }^{1}$ Mapping mashup occupies $38 \%$ of all mashup applications at the time this paper is written according to www.programmableweb.com/mashups
} 